\title{
Critical Micronutrients in Pregnancy, Lactation, and Infancy: Considerations on Vitamin D, Folic Acid, and Iron, and Priorities for Future Research
}

\author{
Maria Hermoso Christiane Vollhardt Karin Bergmann Berthold Koletzko \\ Division of Metabolic and Nutritional Medicine, Dr. von Hauner Children's Hospital, Ludwig-Maximilians-University \\ of Munich Medical Centre, Munich, Germany
}

\section{Key Words}

Iron - Vitamin D · Folic acid - Supplements - Infants •

Pregnant women $\cdot$ Lactating women $\cdot$ EURRECA $\cdot$ Early

Nutrition Academy

\begin{abstract}
The Early Nutrition Academy and the European Commissionfunded EURRECA Network of Excellence jointly sponsored a scientific workshop on critical micronutrients in pregnancy, lactation, and infancy. Current knowledge and unresolved questions on the supply of vitamin $\mathrm{D}$, folic acid, and iron for pregnant women, lactating women, and infants, and their health effects were discussed. The question was addressed of whether, and under which circumstances, supplementation with these micronutrients in addition to usual dietary intakes is advisable. The workshop participants concluded that public health strategies for improving supplementation with these micronutrients in pregnancy, lactation, and infancy are required. Further research priorities should focus on adequately powered human intervention trials to obtain a stronger evidence base for the amounts of vitamin $D$, folic acid, and iron that have optimal effects on health. The conclusions of the workshop should help to inform the scientific community as well as public health policy strategies.
\end{abstract}

Copyright $\odot 2011$ S. Karger AG, Basel
(C) 2011 S. Karger AG, Basel

0250-6807/11/0591-0005\$38.00/0

Fax +41613061234

E-Mail karger@karger.ch

www.karger.com
Accessible online at:

www.karger.com/anm

\section{Introduction}

The Early Nutrition Academy (www.early-nutrition. org) and the European Commission-funded EURRECA Network of Excellence (www.eurreca.org) jointly sponsored a scientific workshop on 'Critical Micronutrients in Pregnancy, Lactation and Infancy' held on June 14-16, 2011, at Tutzing near Munich, Germany. The workshop was organized by the Dr. von Hauner Children's Hospital, University of Munich Medical Centre, and ILSI Europe. Iron, folic acid, and vitamin D supplies in the perinatal period were chosen as the focus of the workshop because many open questions and controversial discussions exist with respect to these nutrients. The supply of vitamin D, folate, and iron is important for the health and well-being of pregnant women and their children. Among scientific bodies worldwide, the adequate supply of these micronutrients during the critical pre- and postnatal periods of life and the possible need for supplementation over and above typical dietary intakes are subjects of ongoing controversy and debate. The World Health Organisation (WHO) reports that on a global basis a large proportion of pregnant women, infants, and children suffer from micronutrient deficiencies [1]. However, there is a lack of harmonized and evidence-based recommendations for the supply of vitamin $\mathrm{D}$, folic acid, and iron during these periods of life. 
The aim of the workshop was to bring qualified experts and new investigators together to discuss current information, conclusions, and open questions and to identify future research priorities. Thirty-three participants from academia and from the industry, including new investigators, attended the workshop. Recent findings on iron, folic acid, and vitamin D supply and effects during pregnancy, lactation, and infancy were presented. Ample time was allocated for discussions to address the question of whether supplementation with the micronutrients in question is necessary or advisable during different trimesters of pregnancy, during lactation, and/or during infancy. In further sessions, research priorities were discussed, and a summary of suggestions for future EU research funding has been forwarded to the Directorate-General Research of the European Commission for consideration. Here we try to summarize some of the main conclusions of the workshop.

\section{Vitamin D}

A large proportion of the global human population shows low concentrations of plasma $25(\mathrm{OH}) \mathrm{D}$, which is considered a very good marker of vitamin D status. Many people do not achieve an adequate vitamin D status because their sun exposure is not sufficient to provide enough endogenous vitamin $\mathrm{D}$ synthesis, while dietary vitamin $\mathrm{D}$ intake is low because there are few food sources.

During pregnancy, vitamin D should support maternal and fetal bone health and enable the maternal immunological adaptation required to maintain a normal pregnancy. It is currently unclear whether or not vitamin D needs are increased during pregnancy. Observational studies indicate that an increased vitamin D status during pregnancy may enhance bone mineralization in the offspring [2]. Evidence from observational studies and also from intervention studies suggests that vitamin $D$ supplementation might benefit immune function and the loss of tolerance occurring in preeclampsia [3]. Observational studies show an association of increased vitamin D status with long-term protection against immunological diseases such as allergic diseases and type 1 diabetes but also with an increased risk of asthma and wheeze [2]. A large proportion of pregnant women are vitamin $\mathrm{D}$ depleted, as shown by low plasma $25(\mathrm{OH}) \mathrm{D}$ concentrations $[2,4]$. An individual assessment of vitamin D status during pregnancy is rather expensive and therefore not feasible on a population basis.
Supplementation of infants, in particular breast-fed infants who receive a lower dietary vitamin $\mathrm{D}$ supply than formula-fed infants, with about 400-500 IU vitamin D per day for the first year of life to prevent rickets is widely accepted and practiced. While infant formula is fortified with vitamin D [5], complementary foods generally do not contain added vitamin $\mathrm{D}$, except for some commercial milk cereals. The provision and implementation of different recommendations for vitamin D supplementation for breast-fed infants and for formula-fed infants appears not to be practically feasible and would create further difficulties in practice due to the significant number of infants receiving both human milk and infant formula in varying proportions.

Future research should be aimed at establishing better evidence of the effects of an increased supply of vitamin $\mathrm{D}$ during pregnancy on the health effects in mothers and offspring from controlled intervention trials, considering the influence of different geographic locations and lifestyles, ethnicity, and the effects of genetic and other interindividual variations. The currently rather limited evidence of the effects of vitamin D supply in women and in infants and young children on health beyond bone [6], such as effects on muscle function and immune response, should be enhanced by adequately designed and powered controlled trials.

\section{Folic Acid}

Folate is essential for the synthesis of DNA and other critical cell components, especially during periods of rapid growth and cell division. Folate requirements are increased during pregnancy due to increased cell multiplication and metabolic turnover, placental and fetal development, growth of the uterus, and maternal blood volume expansion.

The American Institute of Medicine considered the maintenance of a red blood cell (RBC) folate concentration $>340 \mathrm{nmol} / \mathrm{l}$ as the primary indicator of an adequate folate status during pregnancy [7]. A sufficient dietary intake would correspond to the amount of dietary folate equivalents needed to maintain this normal RBC folate status. A low folate status before and during the first trimester of pregnancy is associated with serious congenital anomalies, in particular neural tube defects (NTDs) such as spina bifida and myelomeningocele, but also increased risks for other congenital abnormalities such as congenital heart defects and oral clefts have been proposed [8]. Folic acid or folic acid-containing multivitamin supple- 
mentation from the preconception period through the first trimester of pregnancy effectively reduces NTD occurrence and may reduce cardiovascular and other malformations [9]. It has been suggested that multivitamins with folic acid may have a greater preventive benefit than the use of folic acid alone, but randomized controlled trials with a direct comparison of both strategies have not been performed [9]. Supplementation of 5-methylfolate has also been advocated for the prevention of congenital abnormalities, even though direct evidence from clinical studies is not available [10]. Throughout pregnancy, an adequate folate supply reduces the risk of severe adverse outcomes such as maternal anemia, preeclampsia, placental abruption, low birth weight, and preterm birth.

The workshop participants concluded that a daily intake of $600 \mu \mathrm{g}$ of dietary folate equivalents usually achieves an adequate folate status during pregnancy. Increased consumption of folate-rich foods generally does not reach satisfactory intakes of folate necessary for the prevention of congenital anomalies. Therefore, supplementation of folic acid from enriched foods and/or from supplements is recommended as the effective preventive measure. Women of childbearing age should receive in addition to a folate-rich diet at least $400 \mu \mathrm{g}$ folic acid per day from supplements, fortified foods, or both to prevent NTDs. These recommendations are based on a high evidence level [11] but, nonetheless, in many countries around the world implementation of effective measures to achieve a preventive folic acid intake is failing. This discrepancy constitutes a major public health challenge. For example, in the European Union only a small minority of pregnant women obtain a periconceptional folic acid supply at the recommended preventive dosage, and hence a large number of preventable malformations and severe suffering occur unnecessary. Increased information and motivation for women of childbearing age is needed, for example via campaigns through media, schools, and other settings. The concept of linking information on the preventive effects of folic acid to information on contraceptives was discussed with interest, and it was recommended to carefully evaluate the effects that might be achieved. The workshop participants recognized that promotion of individual folic acid supplementation has not achieved an appreciable reduction of NTD rates on a population level in all countries evaluated [12]. In contrast, folic acid fortification of staple foods such as flour and other cerealbased foods, which is used in about 68 countries around the globe, has been demonstrated to effectively reduce NTDs [13]. Initial concerns that folic acid fortification might increase the risk of neoplasm have not been sub- stantiated [14], but there are reports showing that folic acid fortification of flour in the USA has resulted in a marked decline of deaths from coronary heart disease and particularly from stroke [15], apparently due to a small but consistent blood pressure-lowering effect.

Effects of folic acid supplementation in addition to a reasonable dietary intake during the second and third trimesters of pregnancy on maternal and offspring health are not well documented. There is no conclusive evidence to support continued supplementation of pregnant women after the first semester of pregnancy, but there are also no indications of untoward effects. Further studies on this question are needed.

Further research should investigate the mechanisms of risk reduction of NTDs by folates, which could inform more targeted preventive strategies and options for the evidence-based use of different metabolites. The effects of folic acid alone and in combination with multivitamin or multimicronutrient supplements should be better documented. The effects of an enhanced supply of folic acid or other folates in the second and third trimesters of pregnancy in infants and young children and also in the general population should be explored in greater detail. The impact of folate supply before and during pregnancy on DNA methylation and possible associated biological effects should be investigated. The feasibility, effects, and health economic impact of different strategies towards improving folate status in European populations should be evaluated.

\section{Iron}

Iron deficiency anemia (IDA) is the most frequent form of anemia in pregnancy, and the occurrence of IDA increases the risk of preterm delivery and low birth weight. Moreover, iron is essential for normal fetal development, including brain development [16]. Therefore, IDA in pregnant women must be prevented. The diet before and during pregnancy should be rich in bioavailable iron. In addition, supplementation of all pregnant women with a proven effective iron dose (e.g. 30-40 mg ferrous iron) has been suggested [17]. However, there are concerns about a lack of adequate benefit of such an approach while there are adverse effects particularly in iron-sufficient women. Therefore, a more desirable option would be targeting supplementation to pregnant women at risk of IDA, e.g. with serum ferritin levels $<70 \mu \mathrm{g} / \mathrm{l}$.

In infancy and early childhood, iron remains a critical substrate due to the rapid growth, development, and he- 
moglobin expansion during this period of life. The considerable iron deposited at birth can become exhausted from the 5th to the 7th month of life onwards in healthy breast-fed infants born at full term because human breast milk has a low iron content. Hence, the risk of developing IDA in those infants is high from the end of the first half of the first year of life onwards. It is important to prevent IDA not only because of the direct consequences of anemia but also because iron is critical for brain development and function. IDA deficiency in infancy has been associated with marked adverse effects on later neurodevelopment in several case control studies [18]. In affluent populations such as those in European countries, healthy breast-fed infants generally do not need iron supplements, and infant formulae do not need to provide high iron contents during the first months of life when iron stores are well filled and iron absorption is low [19]. From the 5 th to the 7th month of age onwards, a good supply of well bioavailable iron should be provided with complementary feeding in affluent populations [20], whereas complementary feeding should not be introduced before the 7th month of life in breast-fed infants in low-income countries with a high risk of infectious diarrhea. Iron supplements should not be given to iron-sufficient infants before the 7th month of age because they may induce adverse effects, e.g. on length-wise growth [21], and the effects of iron supplements on the early development of gut microbiota and associated effects remain to be elucidated [22]. However, iron supplements are regularly needed for preterm and low-birth-weight infants and for exclusively breast-fed term infants in low-income countries, and one needs to weigh the benefits against the reported risks of iron supplementation of infants and children in endemic malaria areas where increases in morbidity and mortality have been reported [22].

With respect to priorities for further research on perinatal iron supply, data should be collected from observational studies on iron intake and iron status in pregnant women, infants, and toddlers in Europe, considering modifying factors such as dietary choices, iron absorption, and genetic variation. Further randomized clinical trials testing the effects of different doses of iron supplements for pregnant women on maternal and infant outcomes are needed. The effect of iron supply and status in breast-fed infants and in infants randomized to infant formula with different iron concentrations (e.g. in the range of $2-12 \mathrm{mg} / \mathrm{l}$ ) in a European setting on outcomes such as motor and cognitive development, IDA, gut microbiota, infections, and immune response should be investigated, preferably with a long-term follow-up of sub- jects up to school age. Moreover, the effects of a different iron supply during the second year of life, e.g. with ironfortified milk compared to regular cow's milk, should be explored, considering outcomes similar to those mentioned above for infants. Future observational and intervention studies should take advantage of modern methods to assess iron metabolism such as measures of hepticin and non-transferrin-bound iron to assess gut microbiota development, metabolomic response, genotype, and epigenetic effects.

\section{General Conclusions}

Public health strategies for effectively improving the supply of vitamin D and folic acid, and in selected individuals also of iron, for pregnant and lactating women as well as their infants are urgently needed. Further research is needed with adequately powered, controlled human intervention studies to obtain a stronger evidence base for the amounts of supplied vitamin D, folic acid, and iron that have optimal effects on short- and long-term health. In the case of vitamin D and folic acid, strategies for fortification of food products should be explored and evaluated.

\section{Acknowledgements}

The workshop was financially supported by the EURRECA Network of Excellence, which is financially supported by the Commission of the European Communities, specific research technology and development program 'Quality of Life and Management of Living Resources', within the Sixth Framework Programme, contract No. 036196. This publication does not necessarily reflect the Commission's views or its future policy in this area. Additional support from Danone Research, Merck, and DSM is gratefully acknowledged. The following workshop participants were rapporteurs for the sessions on research priorities: Eline van der Beek, Jan de Vries, and Magnus Domellöf.

\section{Workshop Participants}

Martine Alles, Wageningen, The Netherlands; Eline van der Beek, Singapore; Cristiana Berti, Milan, Italy; Karin Bergmann, Munich, Germany; Hans Konrad Biesalski, Stuttgart, Germany; Heike Bischoff-Ferrari, Zürich, Switzerland; Stefanie Brunner, Munich, Germany; Irene Cetin, Milan, Italy; Andrew Czeizel, Budapest, Hungary; Emma Derbyshire, Manchester, UK; Magnus Domellöf, Umeå, Sweden; Dariusz Gruszfeld, Warsaw, Poland; Maria Hermoso, Munich, Germany; Helmut Heseker, Paderborn, Germany; Richard Hurrel, Zürich, Switzerland; Eline Hypponen, London, UK; Marta Jeruszka-Bielak, Warsaw, Poland; Berthold 
Koletzko, Munich, Germany; Marzena Kucia, Warsaw, Poland; Jacqueline Kung'u, Nairobi, Kenya; Yvonne Lamers, Vancouver, B.C., Canada; Christophe Matthys, Leuven, Belgium; Nils Milman, Copenhagen, Denmark; Luis Moreno Aznar, Zaragoza, Spain; Daniela Much, Munich, Germany; Dominique Roberfroid, Antwerp, Belgium; Kathrin Rauh, Munich, Germany; John Scott, Dublin, Ireland; Christiane Vollhardt, Munich, Germany; Jan de Vries, Gorssel, The Netherlands; Peter Weber, Basel, Switzerland; Marisol Warthon Medina, Preston, UK, and Marion Wenzel, Darmstadt, Germany.

\section{Disclosure Statement}

None of the authors has a personal or financial conflict of interest.

\section{References}

1 Lindsay Allen, Bruno de Benoist, Omar Dary, Richard Hurrell (eds): Guidelines on food fortification with micronutrients. Geneva, World Health Organization, Food and Agricultural Organization of the United Nations, 2006

2 Bischoff-Ferrari HA: Vitamin D - role in pregnancy and early childhood. Ann Nutr Metab 2011;59:17-21.

3 Hyppönen E: Preventing vitamin D deficiency in pregnancy - importance for the mother and child. Ann Nutr Metab 2011;59:28-31.

4 Biesalski HK: Vitamin D recommendations - beyond deficiency. Ann Nutr Metab 2011;59:10-16.

5 Koletzko B, Baker S, Cleghorn G, Neto UF, Gopalan S, Hernell O: Global standard for the composition of infant formula: recommendations of an ESPGHAN coordinated international expert group. Pediatr Gastroenterol Nutr 2005;41:584-599.

6 Moreno LA, Valtueña J, Pérez-López F, González-Gross M: Health effects related with low vitamin D concentrations: beyond bone metabolism. Ann Nutr Metab 2011;59: 22-27.

7 Institute of Medicine: Dietary Reference Intakes for Thiamin, Riboflavin, Niacin, Vitamin B6, Folate, Vitamin B12, Pantothenic Acid, Biotin, and Choline. Washington, $\mathrm{Na}$ tional Academy Press, 1998.
8 Scott J: Folic acid consumption throughout pregnancy - differentiation between trimesters. Ann Nutr Metab 2011;59:46-49.

9 Czeizel AE: Periconceptional folic acid-containing multivitamin supplementation for prevention of neural tube defects and cardiovascular malformations. Ann Nutr Metab 2011;59:38-40

10 Lamers Y: Folate recommendations for pregnancy, lactation, and infancy. Ann Nutr Metab 2011;59:32-37.

11 De-Regil LM, Fernandez-Gaxiola AC, Dowswell T, Pena-Rosas JP: Effects and safety of periconceptional folate supplementation for preventing birth defects. Cochrane Database Syst Rev 2010:CD007950.

12 Botto LD, Lisi A, Robert-Gnansia E, Erickson JD, Vollset SE, Mastroiacovo P, Botting B, Cocchi G, de Vigan C, de Walle H, Feijoo M, Irgens LM, McDonnell B, Merlob P, Ritvanen A, Scarano G, Siffel C, Metneki J, Stoll C, Smithells R, Goujard J: International retrospective cohort study of neural tube defects in relation to folic acid recommendations: are the recommendations working? BMJ 2005;330:571.

13 Heseker H: Folic acid and other potential measures in the prevention of neural tube defects. Ann Nutr Metab 2011;59:41-45.

14 European Food Safety Authority: EFSA meeting summary report: folic acid - an update on scientific developments. Uppsala, 2010 .
15 Yang QH, Botto LD, Erickson JD, Berry RJ, Sambell C, Johansen H, Friedman JM: Improvement in stroke mortality in Canada and the United States, 1990 to 2002. Circulation 2006;113:1335-1343.

16 Cetin I, Berti C, Mandò C, Parisi F: Placental iron transport and maternal absorption. Ann Nutr Metab 2011;59:55-58.

17 Milman N: Iron in pregnancy - how do we secure an appropriate iron status in mother and child? Ann Nutr Metab 2011;59:50-54.

18 Lozoff B, Beard J, Connor J, Felt B, Georgieff $\mathrm{M}$, Schallert T: Long-lasting neural and behavioral effects of iron deficiency in infancy. Nutr Rev 2006;64:S34-S43.

19 Domellöf M: Iron requirements in infancy. Ann Nutr Metab 2011;59:59-63.

20 Agostoni C, Decsi T, Fewtrell M, Goulet O, Kolacek S, Koletzko B, Michaelsen KF, Moreno L, Puntis J, Rigo J, Shamir R, Szajewska H, Turck D, van Goudoever J: Complementary feeding: a commentary by the ESPGHAN committee on nutrition. J Pediatr Gastroenterol Nutr 2008;46:99-110.

21 Dewey KG, Domellof M, Cohen RJ, Landa Rivera L, Hernell O, Lonnerdal B: Iron supplementation affects growth and morbidity of breast-fed infants: results of a randomized trial in Sweden and Honduras. J Nutr 2002; 132:3249-3255.

22 Hurrell R: Safety and efficacy of iron supplements in malaria endemic areas. Ann Nutr Metab 2011;59:64-66. 